\title{
Reactivity of Fine Quartz in Presence of Silica Fume and Slag
}

\author{
Karima Arroudj ${ }^{1}$, Abdelfetah Zenati ${ }^{2}$, Mohamed Nadjib Oudjit ${ }^{1}$, Abderrahim Bali ${ }^{2}$, \\ Arezki Tagnit-Hamou ${ }^{3}$ \\ ${ }^{1}$ Laboratory Built in Environnement (LBE), Faculty of Civil Engineering USTHB, Algiers, Algeria \\ ${ }^{2}$ Laboratory of Construction and Environment, ENSP, Algiers, Algeria \\ ${ }^{3}$ University of Sherbrooke, Faculty of Engineering, Sherbrooke, Canada \\ E-mail:arroudjkarima@yahoo.fr, karroudj@usthb.dz,fatehzenati@yahoo.fr,mohnadoudj@yahoo.fr, ba- \\ lianl@yahoo.fr, Arezki.tagnit-hamou@usherbrooke.ca \\ Received November 10, 2010; revised May 15, 2011; accepted June 1, 2011
}

\begin{abstract}
Dune sand is a very abundant material in south of Algeria. Its high silica content gives a partial pozzolanic reactivity due to its crystalline state. This paper investigates the eVol.ution of cement hydration based on a binary addition particularly the reactivity of dune sand finely ground in the presence of an amorphous addition: silica fume or blast furnace slag. Thus, four combinations of binary additions by substitution have been chosen. The X-ray diffraction analyses performed on cement pastes containing additions have shown the importance of the mineralogy and silica content of additions on their pozzolanic reactivity. Dune sand becomes reactive at long term, especially when associated up to $10 \%$ of amorphous addition (blast furnace slag or silica fume). It results an increasing in mechanical strength of Ultra High Performance Concrete (UHPC) and an improvement of the microstructure.
\end{abstract}

Keywords: Dune Sand, Blast Furnace Slag, Silica Fume, C-S-H, Pozzolanic Reactivity, XRD, Ultra High Performance Concrete

\section{Introduction}

Use of mineral additions in cement industry represents a better way to improve environmental protection and sustainable development. It allows reducing cement consumption and consequently $\mathrm{CO}_{2}$ emission. It was shown that the production of one tone of cement generates nearly one tone of $\mathrm{CO}_{2}$ [1]. Accordingly, the higher the replacement level in cement, the lower $\mathrm{CO}_{2}$ emissions are in the atmosphere.

Ultra high performance concrete (UHPC) is a new concrete containing different active additions. The latter contribute to improve matrix densification by physical and chemical actions.

The chemical action (pozzolanic reaction) is explained by fixing of lime release during cement hydration to form a new generation of C-S-H more compact, which improve performance and long term durability of concrete [2-5].

In Algeria, the steel industry is well developed which represents an important source of slag. In addition, the south of the country is rich in dune sand. This motivate the use of the two both materials as cementitious addition in UHPC [6-8].

In this paper four combinations of binary additions by substitution of $15 \%$ have been studied. To obtain the optimal combination, a series of analysis has been carried out on pastes and concrete.

\section{Experimantation}

\subsection{Materials Used}

In this investigation a CEM II /A cement type and three mineral additions (ground dune sand [DS], ground blast furnace slag [S] and silica fume [SF]) have been used. Their chemical and mineralogical properties presented in Table 1 and Figures 1 and $\mathbf{2}$ show that the $\mathrm{CaCO}_{3}$ has been used as an inert addition in cement manufacturing.

Slag and silica fume have an amorphous structure resulted in a centered halo corresponding to the main line of Melilite and cristobalite respectively. On the other 
Table 1. Physico-chemical and mineralogical properties of cement and additions used.

\begin{tabular}{|c|c|c|c|c|c|c|c|c|c|c|c|}
\hline \multicolumn{12}{|c|}{ Chemical composition } \\
\hline & $\mathrm{SiO}_{2}$ & $\mathrm{Al}_{2} \mathrm{O}_{3}$ & $\mathrm{Fe}_{2} \mathrm{O}_{3}$ & $\mathrm{CaO}$ & $\mathrm{MgO}$ & $\mathrm{SO}_{3}$ & $\mathrm{Na}_{2} \mathrm{O}$ & $\mathrm{K}_{2} \mathrm{O}$ & $\mathrm{Cl}^{-}$ & LOI & $\mathrm{R}$, Ins \\
\hline $\mathrm{C}$ & 19.40 & 03.50 & 03.09 & 62.30 & 01.82 & 01.90 & 00.20 & 00.50 & 00.02 & 06.00 & 01.60 \\
\hline SF & 96.00 & 00.90 & 00.60 & 01.60 & 00.20 & 00.45 & 00.20 & 00.90 & / & l & I \\
\hline DS & 95.00 & 01.15 & 01.27 & 03.70 & 00.15 & 00.08 & 00.00 & 00.40 & 00.00 & 02.50 & 00.20 \\
\hline $\mathrm{S}$ & 39.60 & 09.73 & 03.56 & 41.20 & 03.38 & 00.67 & 00.01 & 00.50 & 00.01 & 01.30 & / \\
\hline \multicolumn{12}{|c|}{ Mineralogical composition } \\
\hline & & $\mathrm{C}_{3} \mathrm{~S}$ & & $\beta \mathrm{C}_{2} \mathrm{~S}$ & & $\mathrm{C}_{3} \mathrm{~A}$ & & $\mathrm{C}_{4} \mathrm{AF}$ & & & \\
\hline $\mathrm{C}$ & & 47.00 & & 20.00 & & 04.00 & & 09.40 & & & \\
\hline SF & \multicolumn{11}{|c|}{ Amorphous diffraction pattern centered at the principal line of Cristobalite with presence of $\mathrm{SiC}$} \\
\hline DS & \multicolumn{11}{|c|}{ Crystallized diffraction pattern: $\alpha$ Quartz type } \\
\hline S & \multicolumn{11}{|c|}{ Amorphous diffraction pattern centered at the principal line of Melilite } \\
\hline \multicolumn{12}{|c|}{ Physical Properties } \\
\hline & \multicolumn{7}{|c|}{ Density } & \multicolumn{4}{|c|}{ Fineness $\left[\mathrm{cm}^{2} / \mathrm{g}\right]$} \\
\hline $\mathrm{C}$ & \multicolumn{7}{|c|}{03.10} & \multicolumn{4}{|c|}{3000} \\
\hline SF & \multicolumn{7}{|c|}{02.20} & \multicolumn{4}{|c|}{200000} \\
\hline DS & \multicolumn{7}{|c|}{02.73} & \multicolumn{4}{|c|}{5000} \\
\hline S & \multicolumn{7}{|c|}{02.80} & \multicolumn{4}{|c|}{3350} \\
\hline
\end{tabular}

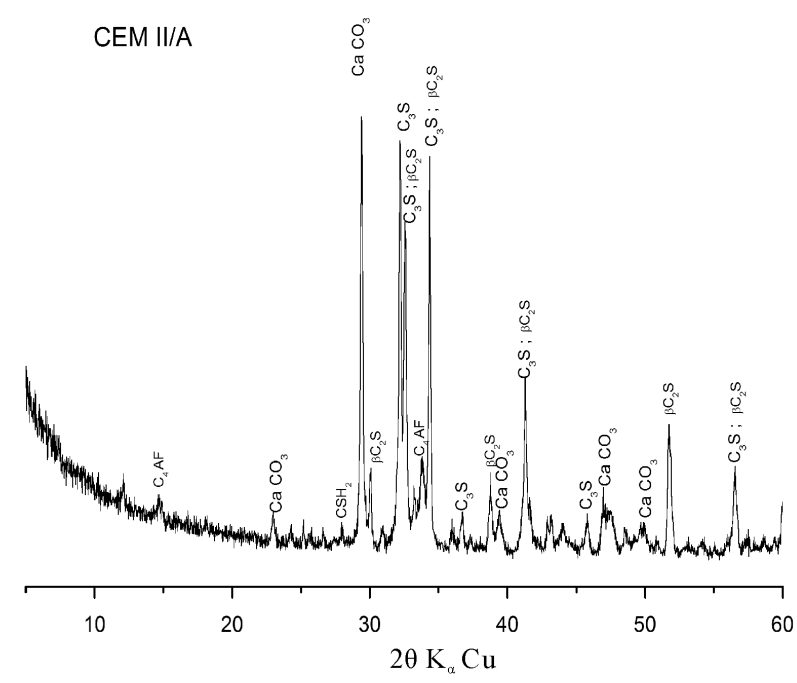

(a)

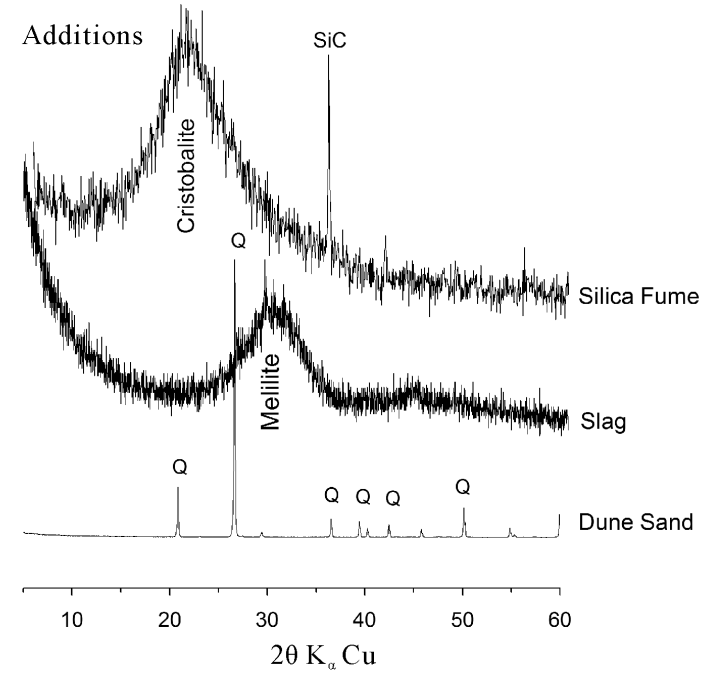

(b)

Figure 1. X- ray diffraction patterns of materials used.

hand, dune sand has a crystalline $\alpha$ Quartz structure with a high content of silica.

Scanning electron micrographs of dune sand show that its structure is formed by amorphous fine particles adsorbed on large crystallized particles. However silica fume is in the form of agglomerates of microspheres with an average diameter $\mathrm{D}=0,136 \mu \mathrm{m}$, which is given by the following relation [9]:

$$
D=\frac{6}{A d_{s}}
$$




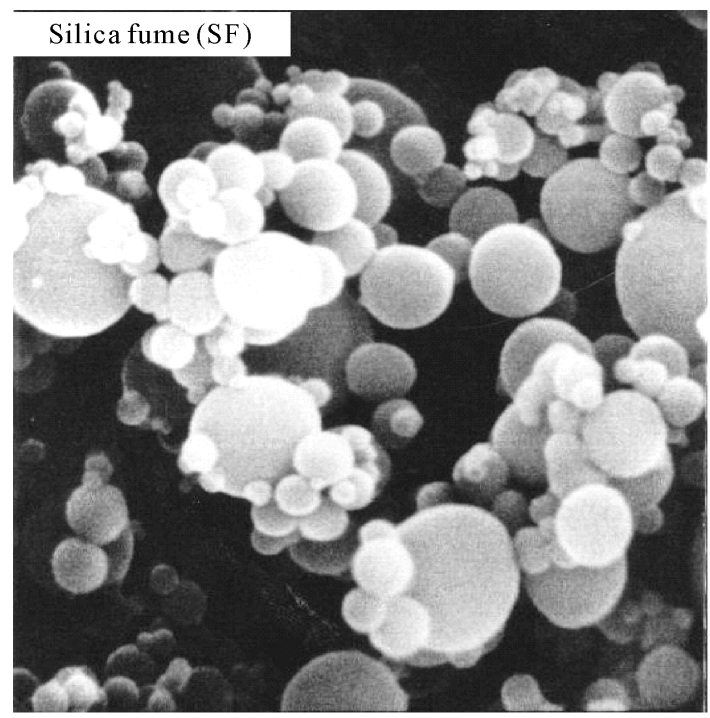

(a)

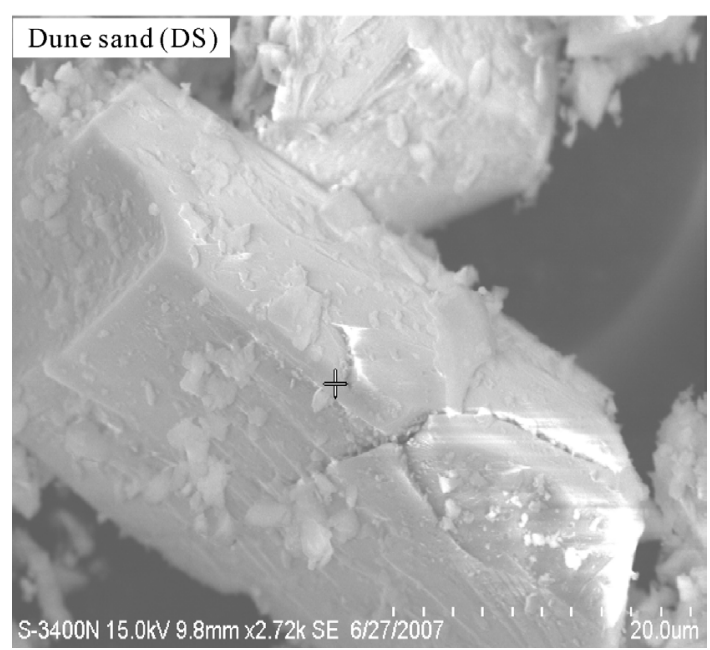

(b)

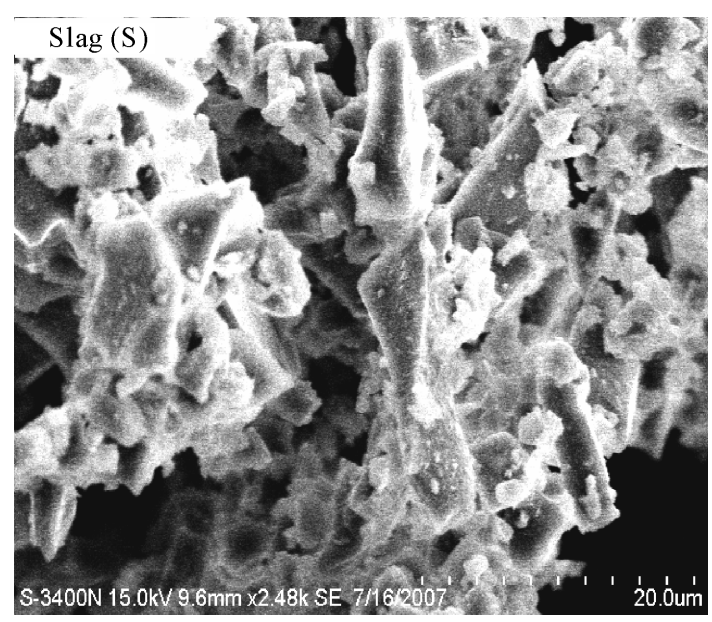

(c)

Figure 2. Scanning electron Micrographs of used additions. where: (D): the average diameter in $\mu \mathrm{m}$; (A) and (ds): the specific area (fineness) in $\mathrm{m}^{2} / \mathrm{g}$ and the density of silica fume respectively

For UHPC, Polycarboxylate based superplasticizer with a density of $1.07 \mathrm{~g} / \mathrm{cm}^{3}$ and dry extract of $30 \%$ was used. The coarse aggregate contains the dune sand with particle size lower than $0.63 \mathrm{~mm}$.

\subsection{Tests on Cement Pastes}

In Table 2, a series of different binary systems [(10 + 5)\% by replacement of cement] are presented.

The monitoring of the eVol.ution of hydration has been established by analyzing pastes using PANalytical's ver- sion X-ray diffractometer, Model X'pert Pro with $\mathrm{CuK} \alpha$ radiation working.

Cement pastes were mixed with a $0.35 \mathrm{~W} / \mathrm{B}$ ratio and analyzed at the anhydrous state, 20 days and 16 months of hydration.

\subsection{Tests on Concrete}

The second part of this research consists of studying the characteristics of UHPC based on dune sand, slag and silica fume.

The formulation of these concrete mixes has been carried out on the basis of that recommended by P. Richard and M. Cheyrezy using a quantity of sand per Vol.ume unit Lower than 0.83 times the apparent density of sand [10-12].

The use of this sand in its natural state has an economical advantage. Its spherical form reduces water requirement. In addition, the fine practical size (fineness modulus $M_{f}<1$ ) allows a gain of grinding energy, and consequently minimization of micro cracks apparition in the grains.

A Polycarboxylate superplasticizer with $\mathrm{pH}$ of 5-6, density of $1.07 \mathrm{gm} / \mathrm{cm}^{3}$ and dry extract of $30 \%$ was used in this study.

For concrete mixes, a $\mathrm{W} / \mathrm{B}$ ratio of 0.24 and a superplasticizer dosage of $1.8 \%$ dry extract have been used.

The series of different concrete mixes per meter cube of concrete are summarized in Table 3.

Compressive strength tests allow determining the po-

Table 2. Compositions of the studied cement pastes.

\begin{tabular}{ccccc}
\hline & C (\%) & SF (\%) & DS (\%) & S (\%) \\
\hline C+SF+DS & 85 & 10 & 5 & $/$ \\
C+DS+SF & 85 & 5 & 10 & $/$ \\
C+S+DS & 85 & $/$ & 5 & 10 \\
C+DS+S & 85 & $/$ & 10 & 5 \\
\hline
\end{tabular}


Table 3. Concrete mixes and their activity indices.

\begin{tabular}{|c|c|c|c|c|c|c|}
\hline \multicolumn{7}{|c|}{ Composition of concrete $\left(\mathrm{Kg} / \mathrm{m}^{3}\right.$ of concrete) } \\
\hline & Cement & \multicolumn{2}{|c|}{ Natural sand } & $S F$ & $S$ & DS \\
\hline UHPC control & 882 & \multicolumn{2}{|c|}{1235} & -- & -- & -- \\
\hline UHPC 1 & 750 & \multicolumn{2}{|c|}{1235} & 88 & -- & 44 \\
\hline UHPC 2 & 750 & \multicolumn{2}{|c|}{1235} & 44 & -- & 88 \\
\hline UHPC 3 & 750 & \multicolumn{2}{|c|}{1235} & -- & 88 & 44 \\
\hline UHPC 4 & 750 & \multicolumn{2}{|c|}{1235} & -- & 44 & 88 \\
\hline \multicolumn{7}{|c|}{ Pozzolanic activity index (AI) } \\
\hline Age (day) & 3 & 7 & 14 & & 28 & 90 \\
\hline UHPC control & 100 & 100 & 100 & & 100 & 100 \\
\hline UHPC 1 & 91.4 & 101 & 105 & & 104.5 & 120 \\
\hline UHPC 2 & 88 & 98 & 100 & & 99 & 97 \\
\hline UHPC 3 & 89.6 & 99 & 100 & & 97.5 & 100.3 \\
\hline UHPC 4 & 85 & 90.3 & 95.7 & & 96 & 97.3 \\
\hline
\end{tabular}

zzolanic activity index (AI), which is the ratio between compressive strength of concrete containing additions $\left(\sigma_{c}\right)$ to those without additions ( $\left.\sigma_{\text {control }}\right)$ :

$$
A I=\frac{\sigma_{c}}{\sigma_{\text {control }}}
$$

The obtained compressive strength are the average of test results on three mortar specimens $40 \mathrm{~mm} \times 40 \mathrm{~mm} \times$ $160 \mathrm{~mm}$.

\section{Results and Discussion}

The portlandite $\left[\mathrm{Ca}(\mathrm{OH})_{2}\right]$ is one of the main hydration products of calcium silicates. Their fixation by silica from the additions results in the formation of a second generation of C-S-H. This generates an improvement in the compactness of cementitious matrix of concretes $[13,14]$.

\subsection{Reactivity of Quartz Crystals}

Analysis of pastes by XRD return to compare the intensities of Portlandite peak (P), calcium silicates peak $\left(\mathrm{C}_{3} \mathrm{~S}\right.$; $\beta \mathrm{C}_{2} \mathrm{~S}$ ) formed during hydration and Quartz peak (Q) containing in dune sand.

The eVol.ution of hydration of cement pastes is presented in Figure 3. The Portlandite peak intensities, as well as that of quartz and calcium silicates decrease with time. This explains that the pozzolanic reaction of the dune sand has occurred whatever the considered combination of addition.

\subsection{Influence of the Mineralogical Structure of the Addition}

Pastes with high quartz content (C + 10\% DS + 5\% SF and $C+10 \%$ DS $+5 \%$ S) consume less Portlandite than pastes with high amorphous addition content (C + 10\% $\mathrm{SF}+5 \% \mathrm{DS}$ and $\mathrm{C}+10 \% \mathrm{~S}+5 \% \mathrm{DS}$ ). This is reflected by the low intensities of Portlandite peaks in the later pastes as shown on Figure 4. The vitreous state of the addition has a great influence on its pozzolanic reactivity [15].

\subsection{Influence of Silica Content}

The hydration of cement containing $10 \%$ SF $+5 \%$ DS is better than that containing $10 \% \mathrm{~S}+5 \% \mathrm{DS}$. A large difference in peak intensities of Portlandite and quartz has been observed. This is explained by the high pozzolanic reactivity of the SF due to its high silica content and high finesse. This result is in accordance with some other investigations on lime pastes based on the same additions. The area of the main peak of portlandite (centered at the ray $d=2.628 \AA ⿱$ ) ) was significantly lower compar atively to other pastes [7].

The dune sand exhibits a better pozzolanic reactivity in presence of silica fume rather than in presence of slag. This explains the low peak intensities of quartz at early and later term in the $\mathrm{X}$ - ray diffraction patterns presented in Figure 5.

\subsection{Characterization of concretes containing additions}

At early age, activity indices of UHPC with additions were lower than that of control due to the effect of cement replacement [16,17].

At 7 days, concrete containing a high proportion of amorphous additions (UHPC 1 and 3) have similar indices to that of control. This reflects the eVol.ution of the pozzolanic reaction of amorphous additions.

Concrete containing high proportion of SD (UHPC 4) have lower indices at early age. While at later age, it presents similar indices to those of UHPC 2 containing $5 \% \mathrm{SF}$. This explains that there is no effect of SD on pozzolanic reactivity at early age. As a result, the pozzolanic reactivity of additions at this age is more influenced by the amorphous structure than by fineness [15, $18,19]$.

\section{Pozzolanic activity at later age}

At later ages UHPC 1 had higher reactivity indices 


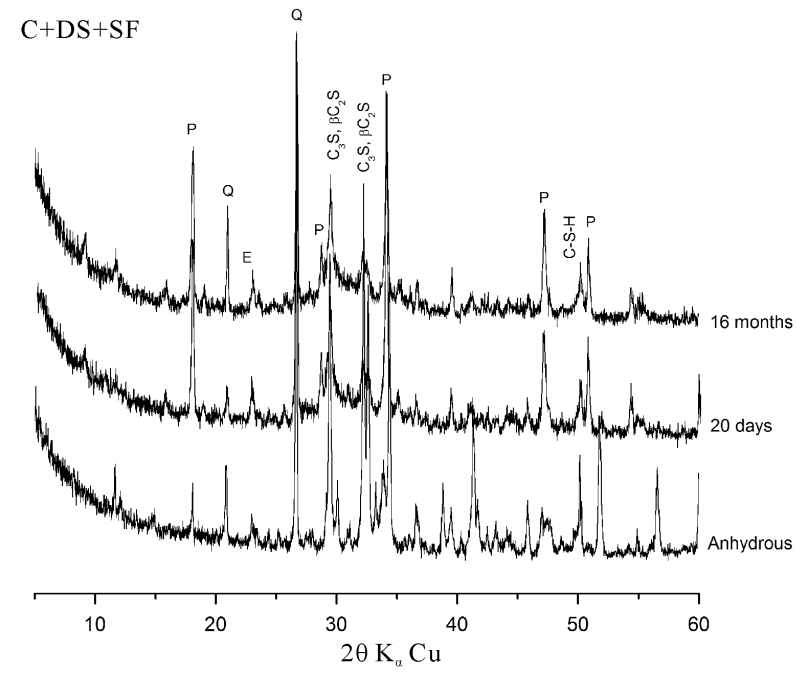

(a)

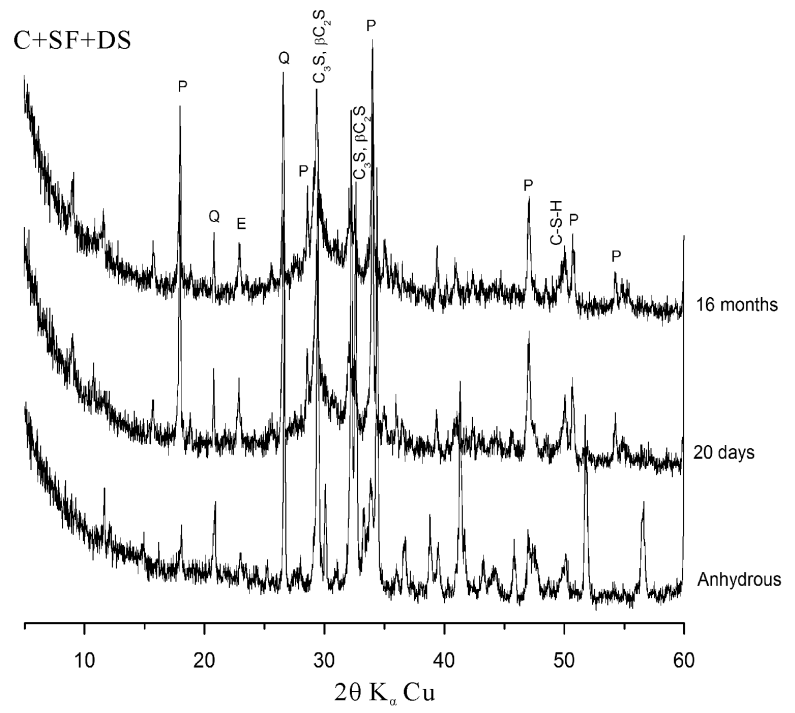

(c)

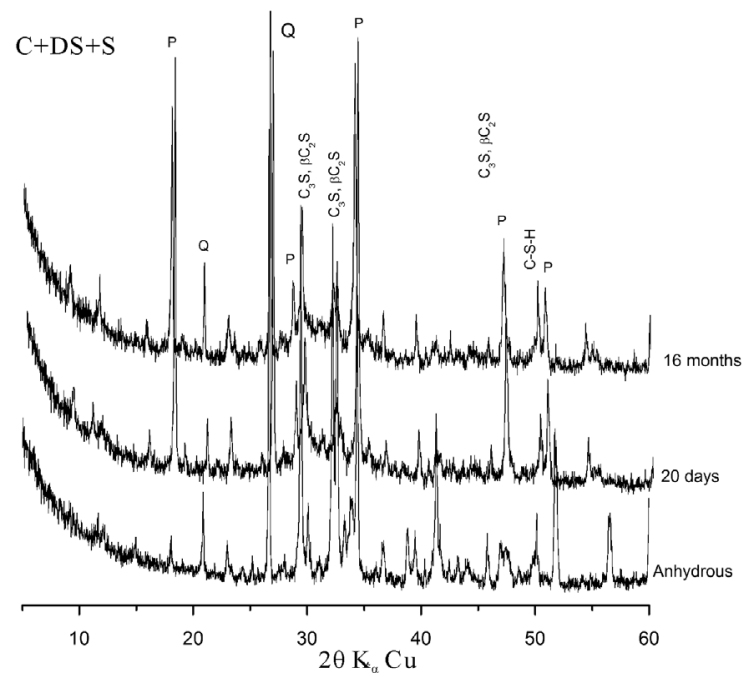

(b)

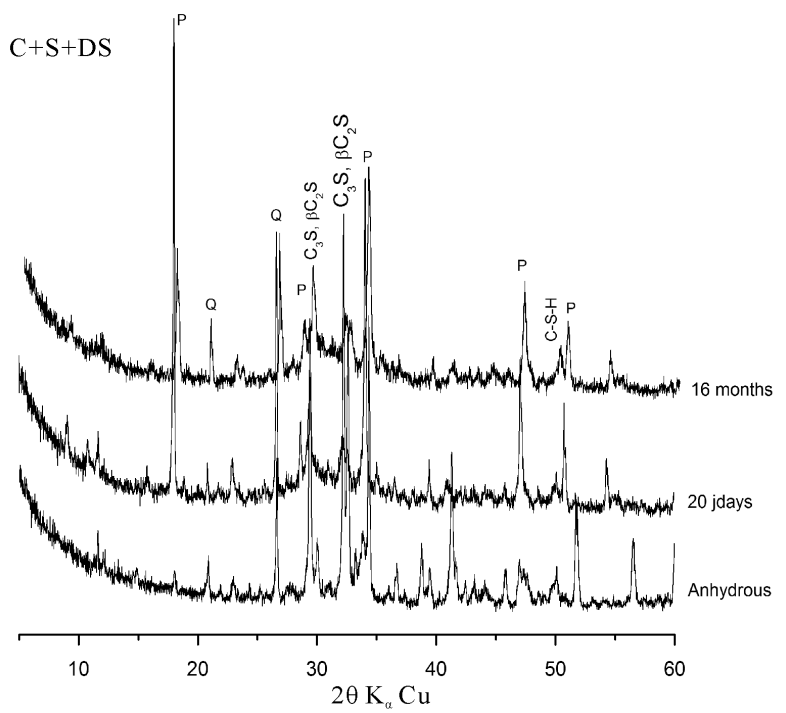

(d)

Figure 3. X- ray diffraction patterns of different pastes as a function of time.

than UHPC 3. This proves that despite the crystalline structure of DS, it became more reactive at later age due to a synergetic interaction with SF. On the other hand, UHPC 2 showed reduced indices compared to UHPC 1. This is in agreement with the study done on pastes with binary additions.

In the case of UHPC 3 , the reactivity index was similar to that of the control and greater than that of UHPC 4. This also means that higher cement replacement levels of DS in presence of slag is not recommended. Then, and as a conclusion of this part of the study, hydrated lime liberated during cement hydration is well fixed in the presence of a large proportion of an amorphous material. These results confirm also what was already found $[6,7]$.

\subsection{Microstructure of Concrete}

The SEM-EDX analysis of concrete samples hydrated at 28 days are presented in Figure 6.

The matrix is very dense in the concrete based addition than in the control. The C/S ratio is high in the control concrete $(\mathrm{C} / \mathrm{S}=1.75)$ which is in agreement with the literature $[17,20,21]$. While, this ratio is lower in the other concretes due to the presence of pozzolanic materi- als $(\mathrm{C} / \mathrm{S}=1.1$ in UHPC 1 and 3 and $\mathrm{C} / \mathrm{S}=1.35$ in UHPC 2 and 4).

The decrease in $\mathrm{C} / \mathrm{S}$ ratio is explained by the low concentration of $\mathrm{Ca}^{2+}$ ions in the presence of additional amorphous silica than in the presence of crystalline 


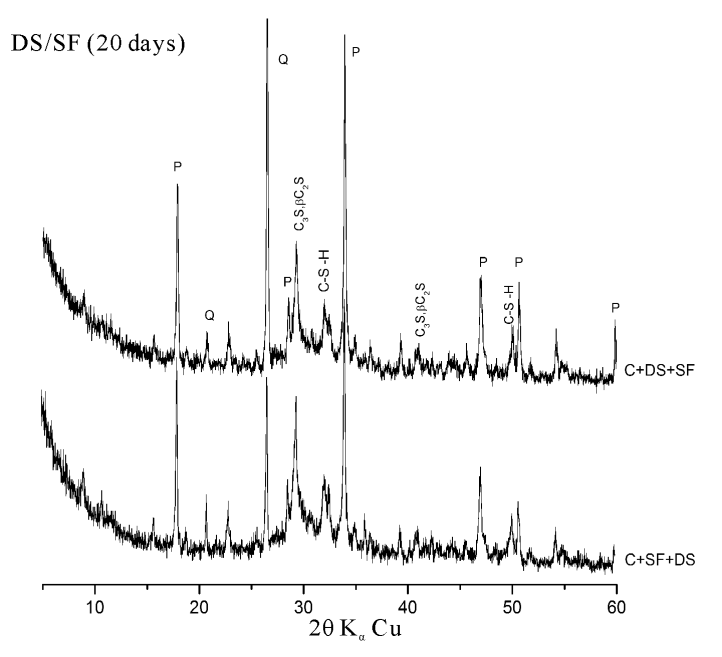

(a)

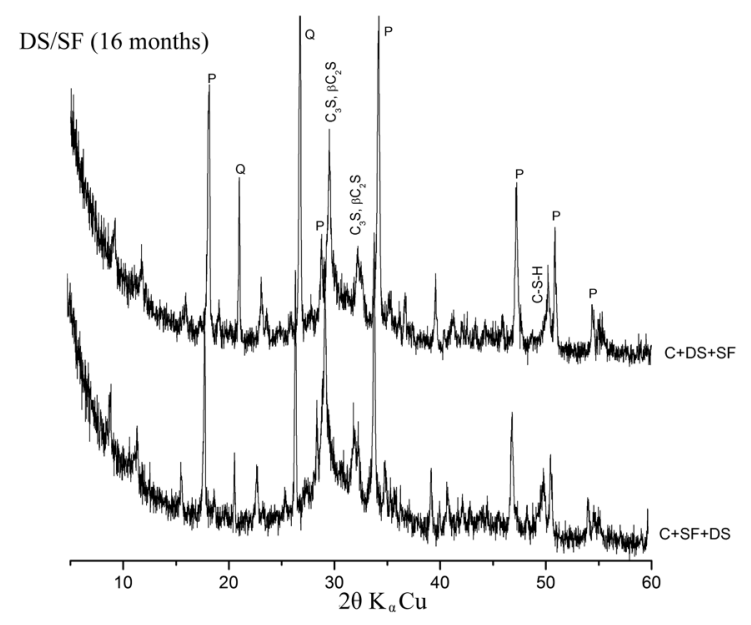

(c)

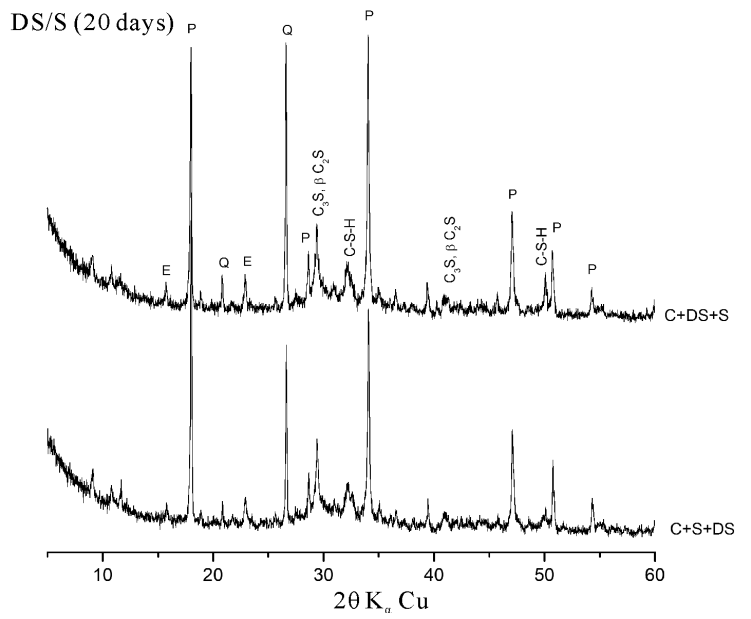

(b)

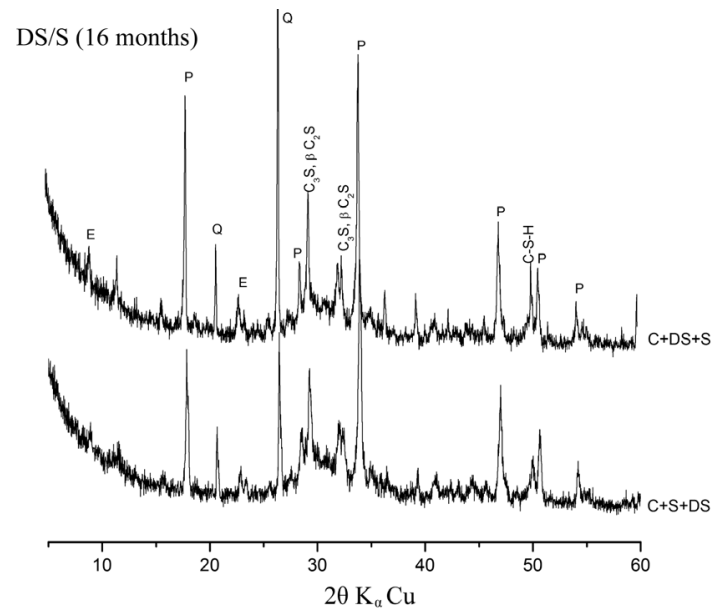

(d)

Figure 4. Influence of the mineralogical structure on pozzolanic reactivity.

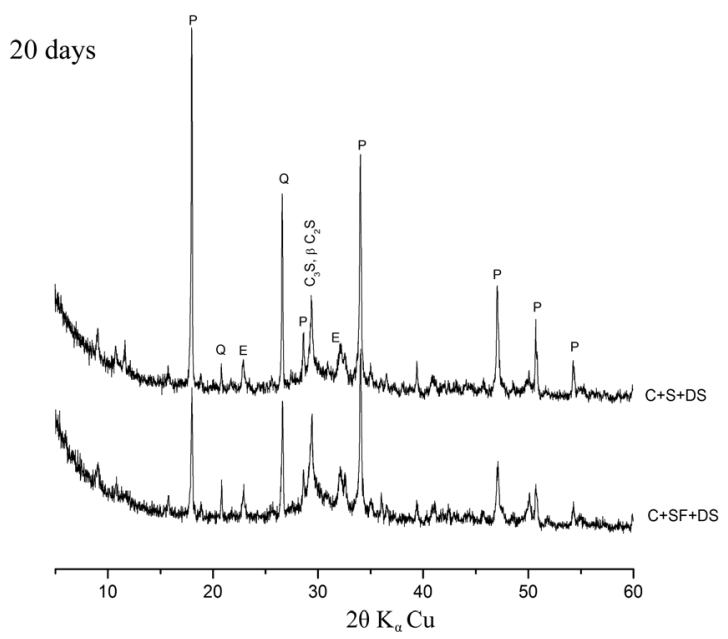

(a)

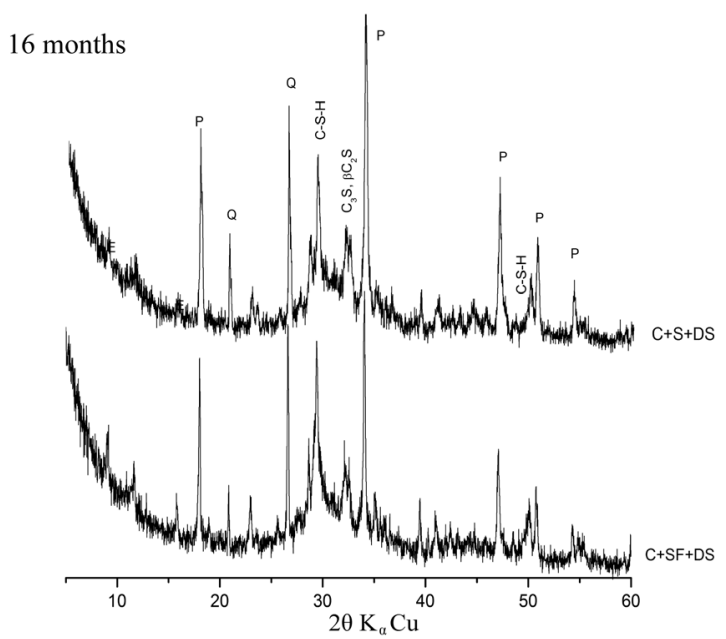

(b)

Figure 5. Influence of silica content on pozzolanic reactivity. 


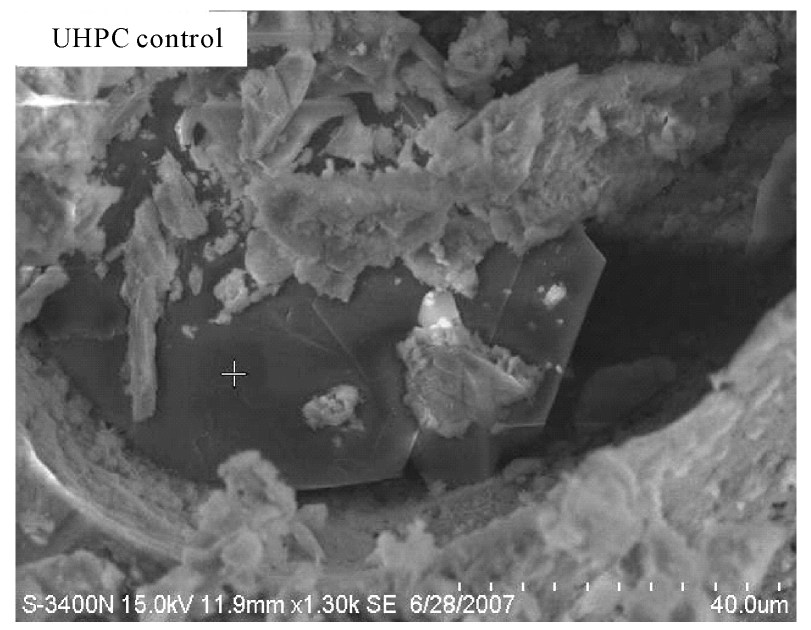

(a)

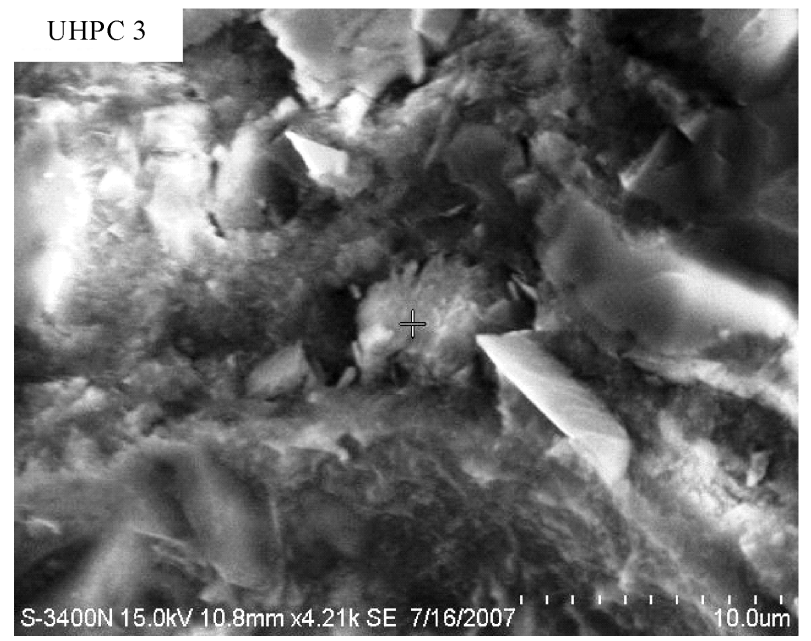

(c)

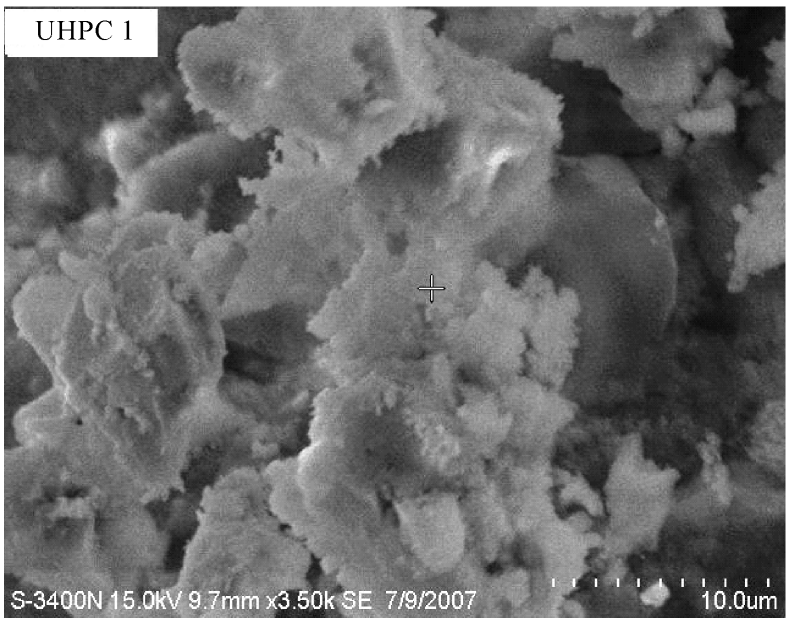

(b)

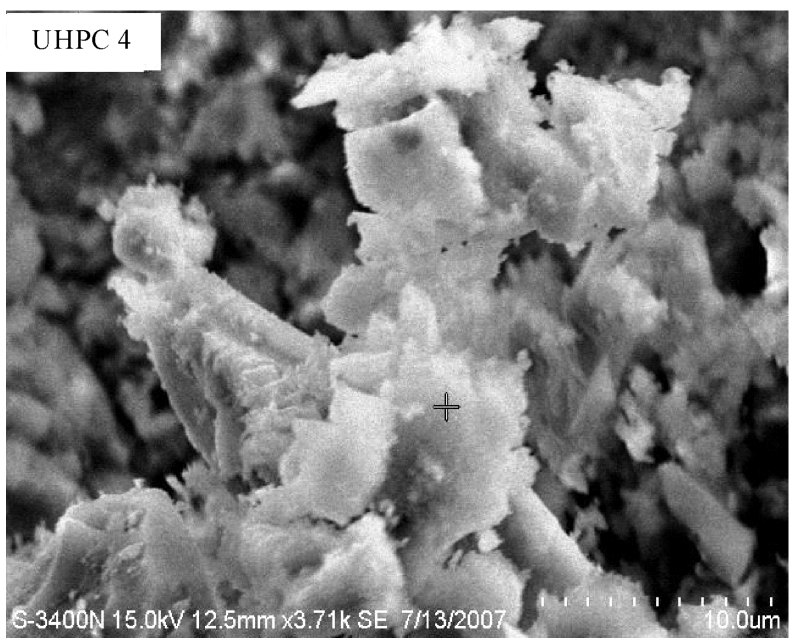

(d)

Figure 6. Microstructure of C-S-H of different concrete mixes.

structure $[3,20,22]$.

\section{Conclusions}

In this study, it could be concluded that the mineralogy of additions has a great influence on the pozzolanic reactivity at early ages.

The presence of fine amorphous population on grains of ground dune sand leads to a partial pozzolanic reactivity enhanced by the presence of $10 \%$ amorphous silica.

The introduction of reactive additions produces a densification of formed $\mathrm{C}-\mathrm{S}-\mathrm{H}$ and a decrease in their stoichiometric ratios $\mathrm{C} / \mathrm{S}$.

The availability of slag and dune sand in Algeria leads to recommend UHPC 3 with $10 \% \mathrm{~S}+5 \%$ DS as the optimal composition meeting the dual goals of economic and environmental benefits. It provides the same me- chanical properties as those of the control and the C-S-H structure is similar to that of UHPC 1 (10\% SF and 5\% DS).

\section{References}

[1] P.-C. Aïtcin, "High Performance Concrete," Eyrolles Editions, 2001.

[2] P.-K. Mehta and O.-E. Gjorv, "Properties of Portland Cement Concrete Containing Fly Ash and Condensed Silica Fume," Cement and Concrete Research, Vol. 12, No. 5, 1982, pp. 587-595. doi:10.1016/0008-8846(82)90019-9

[3] J.-P. Gleize, A. Müller and H.-R. Roman, "Micro-Structural Investigation of Silica Fume- Cement-Lime Mortar," Cement and Concrete Composites, Vol. 25, No. , 2003, pp. 171-175. doi:10.1016/S0958-9465(02)00006-9

[4] A.-M. Poppe and G. De Schutter, "Cement Hydration in 
the Presence of High Filler Contents,” Cement and Concrete Research, Vol. 35, No. , 2005, pp. 2290-2299. doi:10.1016/j.cemconres.2005.03.008

[5] S.-K. Agarwal, "Pozzolanic Activity of Various Siliceous Materiels," Cement and Concrete Researsh, Vol. 36, No. , 2006, pp. 1735-1739. doi:10.1016/j.cemconres.2004.06.025

[6] M. N. Oudjit, K. Arroudj, M. Lanez, A. Bali and A. Tagnit-Hamou, "Pozzolanic Reactivity of Siliceous Wastes," $12^{\text {th }}$ International Congress on the Chemistry of Cement (ICCC 2007), Montreal, Canada, 2007.

[7] K. Arroudj, G. Fares, A. Zenati, A. Tagnit-Hamou and M. N. Oudjit, "Hydration of Cement in the Presence of Slag and Dune Sand," Tenth ACI International Conference on Recent Advances in Concrete Technology and Durability, Seville, Spain, 2009.

[8] A. Zenati, K. Arroudj, M. Lanez and M. N. Oudjit, "Influence of Cementitious Additions on Rheological and Mechanical Properties of Reactive Powder Concrete,” Physics Procedia, Vol. 2, 2009, pp. 1255-1261.

[9] P.-C. Aïtcin, "Physico-Chemical Characteristics of Condensed Silica Fume," Condensed Silica Fume, Les éditions de l’Université de Sherbrooke, Canada, 1983. doi:10.1016/j.phpro.2009.11.089

[10] P. Richard and M. Cheyrizy, "Composition of Reactive Powder Concretes," Cement and Concrete Research, Vol. 25, No. , 1995, pp. 1501-1511. doi:10.1016/0008-8846(95)00144-2

[11] P. Richard and M. Cheyrizy, "Les Bétons de Poudres Réactives,” Annales de l'Institut Du Bâtiment et des Travaux Publics, No. 532, 1995, pp.85-102.

[12] H. Zanni, M. Cheyrizy, V. Maret, S. Philippot and P. Nieto, "Investigation of Hydration and Pozzolanic Reaction in Reactive Powder Concrete (RPC) Using ${ }_{29} \mathrm{Si}$ NMR,” Cement and Concrete Research, Vol. 26, No. 1, 1996, pp. 93-100. doi:10.1016/0008-8846(95)00197-2

[13] S. Laldji and A. Tagnit-Hamou, "Properties of Ternary and Quaternary Concrete Incorporation New Alterna tive Cementitious Material,” ACI Materials Journal, Vol. , No. , 2006, pp. 103-109.

[14] A. Korpa, T. Kowaldand and R. Tretti, "Hydration Behavior, Structure and Morphology of Hydratation Phases in Advanced Cement-Based Systems Containing Micro and Nano Pozzolanic Additives,” Cement and Concrete Research, Vol. 8, No. , 2008, pp. 955-962. doi:10.1016/j.cemconres.2008.02.010

[15] R. L. Sharmaand and S. P. Pandey, "Influence of Mineral Additives on the Hydrataion Characteristics of Ordinary Portland Cement," Cement and Concrete Research, Vol. 29, No. , 1999, pp. 1525-1529. doi:10.1016/S0008-8846(99)00104-0

[16] M. N. Oudjit, "Réactivité des fumées de silice condensées en présence de chaux ou de ciment Portland," Thèse de Docteur-Ingénieur, INSA-Toulouse, France, 1986.

[17] H. H. Bache, "Densified Cement/Ultra-Fine ParticlesBased Material," Second International Conference on Superplasticizers in Concrete, Ottawa, Canada, 1981.

[18] J.-C. Benezet and A. Benhassaine, "Influence de la taille des particules sur la réactivité pouzzolanique de poudres de quartz,” Bulletin des Laboratoires des Ponts et Chaussées, No. 219, 1999, pp.17-28.

[19] G.-C. Isaia, A.-L.-G. Gastaldiniand and R. Moraes, "Physical and Pozzolanic Action of Mineral Addition on the Mechanical Strength of High-Performance Concrete," Cement and concrete composites, Vol. 25, No. , 2003, pp. 69-76. doi:10.1016/S0958-9465(01)00057-9

[20] V. Baroghel-Bouny, "Caractérisation des pâtes de ciment et des bétons,” Edition:LCPC, France,1994.

[21] H. F. W. Taylor, “Cement Chemistry,” Thomas Telford Editions, 2nd Edition, New York, 1997.

[22] L. Gatty, "Caractérisations microstructurales et microanalytiques des Bétons de Poudres Réactives par microscopies électroniques,” PhD Thesis, Nantes, France, 1996. 